\title{
Volker Musahl, MD. New Associate Editor
}

\author{
Jon Karlsson • Roland Becker $\cdot$ Neil P. Thomas
}

Published online: 28 February 2013

(C) Springer-Verlag Berlin Heidelberg 2013

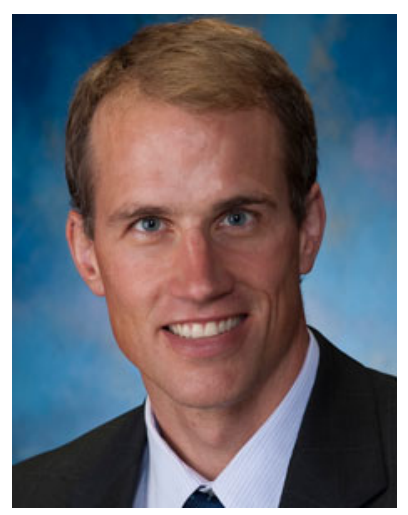

Volker Musahl, MD, has been appointed an Associate Editor of the Knee Surgery Sports Traumatology and Arthroscopy Journal commencing April 2013. He will replace Karl-Peter Benedetto, who resigns after his term of 5 years. Volker has served the journal for several years both as a reviewer and an Editorial Board Member. He trained at the Albert-Ludwigs-University in Freiburg, Germany, graduating in 1998. He then worked at the Martin-Luther-Hospital in Berlin under the leadership of Prof. Peter Hertel. In 2000, he accepted a position as post-

doctoral research fellow at the University of Pittsburgh with Prof. Freddie Fu and Prof. Savio Woo. He finished his specialist training in Orthopaedics Surgery at the University of Pittsburgh in 2008. In 2009, he spent 1 year in a sports medicine and shoulder fellowship with Prof. David Altchek and Prof. Scott Rodeo at the Hospital for Special Surgery in New York.

In 2009, he was appointed Assistant Professor of Orthopaedic Surgery at the UPMC Center for Sports Medicine in Pittsburgh, and in 2011, he was appointed Assistant Professor of Bioengineering in the Swanson School of Engineering at the University of Pittsburgh and the same year was selected a member of the ACL study group. His research work focuses on anatomy and biomechanics of the ACL, clinical examination of the knee and rotatory knee laxity, surgical techniques of ACL reconstruction, and meniscus transplantation. Volker has been a member of ESSKA since 2000 and has been active in the ESSKA programme committee for the next ESSKA Congress (Amsterdam 2014). He is also a member of ISAKOS, AAOS, ORS, AOSSM, AANA, and AGA. In 2013, he was appointed an Associate Professor at the University of Pittsburgh. We welcome Volker to the team of Editors of KSSTA.

J. Karlsson ( $\varangle)$

Department of Orthopaedics, Sahlgrenska University Hospital,

43180 Mölndal, Sweden

e-mail: jon.karlsson@telia.com

R. Becker

Department of Orthopaedic and Traumatology,

City Hospital Brandenburg, Hochstrasse 29,

14770 Brandenburg/Havel, Germany

N. P. Thomas

The Hampshire Clinic, Basing Road, Old Basing,

Basingstoke, Hampshire RG24 7AL, UK 